Nuntius Antiquus, Belo Horizonte, v. 13, n. 2, p. 173-193, 2017

\title{
Aporias nas relações entre tempo e movimento nas Confissões (XI-XII)
}

\section{Aporias Within the Relations Between Time and Movement: Confessions (XI-XII)}

\author{
Maurizio Filippo Di Silva \\ Departamento de Filosofia \\ Universidade Federal do Paraná, Curitiba, Paraná / Brasil \\ maurizio@ufpr.br
}

Resumo: O objetivo deste artigo é o de esboçar as aporias concernentes à relação entre tempo e movimento assim como aparecem nos livros XI e XII das Confessiones de Agostinho. Tendo em vista tal fim, na primeira fase desta pesquisa, analisar-se-á o problema da relação entre tempo e moto com base na interpretação agostiniana das palavras In principio fecit Deus, do primeiro versículo da Gênese. Em seguida, no segundo momento, verificar-se-á o problema de se a matéria ou a forma é a condição da existência do tempo e do movimento, segundo a interpretação agostiniana das palavras caelum et terram de Gênese 1,1. Por fim, nas conclusões, examinar-se-á se as questões mencionadas são autênticas aporias ou se elas exprimem os limites da compreensão humana da autoridade divina (Confessiones, VI).

Palavras-chave: Agostinho; tempo; movimento; matéria; forma.

Abstract: The purpose of this paper is to point out the aporias concerning the relation between time and movement as they appear in books XI and XII of the Confessions of Augustine. With this aim in mind, in the first phase of this research, the problem of the relation between time and movement will be analyzed from the Augustinian interpretation of the words "In principio fecit Deus" from the first verse of Genesis. Then, in the second moment of this research, we will analyze the problem of what, if matter or form, is the condition of the existence of time and movement from the Augustinian interpretation of the words "caelum et terram" of Genesis 1:1. Finally, in the conclusion, it will be examined whether the questions referred to are authentic aporias or if they express the limits of human understanding of divine authority (Confessions, VI).

Keywords: Augustine; time; movement; matter; form. 


\section{Introdução}

O objetivo deste artigo é o de delinear, nas Confessiones de Agostinho, e mais precisamente nos livros XI e XII da obra mencionada, as aporias concernentes à relação entre tempo e movimento assim como aparecem no âmbito da hermenêutica agostiniana de Gn. 1,1. Tendo em vista tal fim, na primeira fase desta pesquisa, analisar-se-á o problema da relação entre tempo e movimento segundo a interpretação agostiniana das palavras No Princípio Deus criou, do primeiro versículo da Gênese. O objetivo desta fase da análise será, mais precisamente, o de colocar em evidência a tese agostiniana referente à existência do tempo e à sua natureza de condição do movimento, para poder apontar o seu contraste com as reflexões agostinianas sobre o moto como fundamento do tempo. Em seguida, isto é, no segundo momento, o intuito será o de esboçar a interpretação agostiniana das palavras céu e terra, do primeiro versículo da Gênese, para esclarecer por que, para Agostinho, a forma é condição da existência do tempo e do moto, e poder, assim, colocar em evidência o contraste dessa tese com a reflexão do Hiponense sobre a matéria enquanto fundamento do movimento e do tempo. Por fim, nas conclusões, analisar-se-á se as questões mencionadas constituem autênticas aporias ou se elas exprimem os limites da compreensão humana das Sagradas Escrituras (Confessiones, VI).

\section{Tempo e movimento: Confessiones, $\mathrm{XI}$}

Como indicado na introdução, o primeiro objetivo destas análises será o de esclarecer se e como, no livro XI das Confessiones, Agostinho esboça o tempo como uma entidade. ${ }^{1}$ Mais precisamente, sendo que,

\footnotetext{
${ }^{1}$ Apesar da sua centralidade na reflexão agostiniana sobre o conceito de tempo, o livro XI das Confessiones não representa o único momento das análises do Hiponense dedicado ao problema da temporalidade. Nesse sentido, cabe sublinhar que, como Catapano (2007, p. 5-47; p. 101-140) observa na sua precisa apresentação dos elementos teóricos do livro XI das Confessiones, a noção de tempo é objeto da reflexão de Agostinho também nas seguintes obras: De immortalitate animae 3, 3; De Genesi adversus Manichaeos I, 2, 3-4; De diversis quaestionibus octoginta tribus 19; De Genesi ad litteram liber
} 
para o Hiponense, todos os seres são criaturas, tratar-se-á de analisar as reflexões de Agostinho sobre a criação, para entender, in primis, se o tempo é um dos seres, e poder, em seguida, analisar a sua relação com o movimento.

As reflexões agostinianas sobre $G n$. 1,1 surgem da exigência de responder a uma célebre objeção relativa à ideia da criação do mundo. Nesse sentido, os Maniqueístas ${ }^{2}$ afirmavam que, se o mundo tivesse sido criado, deveria ter passado do não ser ao ser por causa de uma mudança na vontade divina. Contudo, eles sublinhavam, se a natureza de Deus é imutável, é impossível afirmar que houve uma mudança nela. Ainda mais, acrescentavam, se para guardar tanto a criação do mundo quanto a imutabilidade divina fosse necessário afirmar que não houve mudança em Deus, isso implicaria admitir que o mundo é eterno:

Nonne ecce pleni sunt vetustatis suae qui nobis dicunt: «Quid faciebat Deus, antequam faceret caelum et terram? Si enim vacabat» inquiunt «et non operabatur aliquid, cur non sic semper et deinceps, quemadmodum retro semper cessavit ab opere? Si enim ullus motus in Deo novus extitit et voluntas nova, ut creaturam conderet, quam numquam ante condiderat, quomodo iam vera aeternitas, ubi oritur voluntas, quae non erat? Neque enim voluntas Dei creatura est, sed ante creaturam, quia non crearetur aliquid, nisi creatoris voluntas praecederet. Ad ipsam ergo Dei substantiam pertinet voluntas eius. Quod si exortum est aliquid in Dei substantia, quod prius non erat, non veraciter dicitur aeterna illa substantia; si autem Dei voluntas sempiterna erat, ut esset creatura, cur non sempiterna et creatura? ${ }^{3}$

unus imperfectus 3, 6-8; De Genesi ad litteram (V, 5, 12; VIII, 20, 39); In Iohannis evangelium tractatus 31; De Civitate Dei (XI, 4/2-6; XII,13; XII, 14, 1-2; XII, 15; XII, 16, 1-3; XII, 17; XII, 18, 1-2). No que concerne à noção agostiniana de tempo, cf. também: Callahan (1948); Di Silva (2015, p. 129-148).

${ }^{2}$ Sobre a adesão de Agostinho ao Maniqueísmo, cf.: Decret (1997, p. VII-CXV); Ries (1984, p. 7-26).

${ }^{3} \mathrm{O}$ texto latino das Confessiones em uso neste artigo é o da NBA (2007). 
Certamente estão ainda mergulhados na cegueira do velho homem aqueles que dizem: Que fazia Deus antes de criar o céu e a terra? E acrescentam: Se estava ocioso e nada realizava, por que não ficou sempre assim, continuando a abster-se do trabalho? Se existiu em Deus um movimento novo, uma vontade nova de criar uma criatura que ele ainda não tinha feito antes, como se pode falar de verdadeira eternidade, onde nasce uma vontade que antes não existia? Mas a vontade de Deus não é uma criatura; é anterior a toda criatura, pois nada seria criado se antes não existisse a vontade do Criador. Essa vontade pertence à própria substância de Deus. Mas se algo surgiu na substância de Deus que antes não existia, não é justo denominá-la substância eterna. Pelo contrário, se era eterna a vontade de Deus que existisse a criatura, por que não é eterna também a criatura? (AGOSTINHO, 1984, XI, 10.12)

Na análise desta objeção, Agostinho coloca em evidência, em primeiro lugar, que essa objeção, apesar da sua profundidade, ${ }^{4}$ fundamenta-se em uma falsa ideia da eternidade divina, que é entendida, pelos Maniqueístas, como um permanecer ilimitado no tempo e não como uma absoluta transcendência da temporalidade. ${ }^{5}$ Nesse sentido, o esforço agostiniano caracteriza-se como uma tentativa de conjugar a perfeita imutabilidade e atemporalidade divina com o moto, entendido como o aspecto constitutivo das criaturas. ${ }^{6}$

O fato é que as análises agostinianas concernentes à criação do mundo coincidem com a interpretação de $G n$. 1,1. Nesse contexto teórico, Agostinho esboça, in primis, o sentido da expressão No Princípio, do primeiro versículo da Gênese. O Hiponense afirma que com tal expressão indica-se a Palavra de Deus enquanto instrumento da criação e, logo depois, acrescenta que a Palavra divina é o Verbo eterno, isto é, o Pensamento de Deus, o que sugere, para Agostinho, que Deus criou o mundo pensando:

\footnotetext{
${ }^{4}$ Agostinho (1984, XI, 12.14).

${ }^{5}$ Agostinho (1984, XI, 11.13).

${ }^{6}$ Agostinho (1984, XI, 8.10).
} 
Vocas itaque nos ad intellegendum Verbum, Deum apud te Deum, quod sempiterne dicitur et eo sempiterne dicuntur omnia. Neque enim finitur, quod dicebatur, et dicitur aliud, ut possint dici omnia, sed simul ac sempiterne omnia: alioquin iam tempus et mutatio et non vera aeternitas nec vera immortalitas.

Tu nos chamas então a compreender o Deus Verbo que é Deus contigo, o Verbo que é pronunciado eternamente, e por ele todas as coisas são eternamente proferidas. Pois o que foi dito não foi sucessivamente proferido - uma coisa concluída para que a seguinte pudesse ser dita, mas todas as coisas proferidas simultânea e eternamente. Se assim não fosse, já haveria tempo e mudança, e não verdadeira eternidade e verdadeira imortalidade. (AGOSTINHO, 1984, XI, 7.9)

Contudo, em seguida, aprofundando tal interpretação do primeiro versículo da Gênese, Agostinho coloca em evidência uma dificuldade teórica relativa à relação entre a criação e o movimento das criaturas. De fato, se o mundo é uma criatura e, ao mesmo tempo, se Deus criou o mundo no Verbo, logo, à luz da onisciência e imutabilidade divina, é necessário que todas as criaturas existam simul et semel:

Et ideo verbo tibi coaeterno simul et sempiterne dicis omnia, quae dicis, et fit, quidquid dicis ut fiat; nec aliter quam dicendo facis: nec tamen simul et sempiterna fiunt omnia, quae dicendo facis.

Com esta palavra, que é eterna como tu, enuncias a um só tempo e eternamente tudo o que dizes. E tudo o que dizes que se faça, realiza-se. Não de outro modo, mas somente com a palavra, tu crias. Nem todas as coisas, porém, que crias com a palavra, passam a existir simultaneamente e desde toda a eternidade. (AGOSTINHO, 1984, XI, 7.9)

Como o trecho sugere, tal interpretação da criação do mundo parece implicar a negação do movimento das entidades e da ordem de sucessão dos acontecimentos. De fato, se no Verbo está presente tudo o que é conhecível, e, ao mesmo tempo, se Deus cria o mundo pensando, 
logo a criação teria de vir a ser na sua totalidade e sem alguma forma de mudança ou desenvolvimento, o que é evidentemente contrário ao que é atestado pela nossa experiência. Sendo assim, torna-se necessário, para Agostinho, esboçar por que e como a criação não elimina o movimento das criaturas. Tendo em vista tal fim, o Hiponense especifica o que pertence à Sabedoria de Deus e afirma que nela encontra-se, também, o conhecimento da ordem temporal dos acontecimentos. Isso significa que, se Deus criou o mundo no Verbo e se no Verbo está presente a ordem dos acontecimentos, logo tudo o que acontece tem de acontecer conforme a ordem conhecida por Deus:

Cur, quaeso, Domine Deus meus? Utcumque video, sed quomodo id eloquar nescio, nisi quia omne, quod esse incipit et esse desinit, tunc esse incipit, et tunc desinit, quando debuisse incipere vel desinere in aeterna ratione cognoscitur, ubi nec incipit aliquid nec desinit.

Senhor meu Deus, eu me pergunto sobre o porquê de tudo isso. De certo modo já o vejo, mas não sei como exprimi-lo. Talvez assim: Todo ser que começa a existir e tem um fim, começa e acaba quando a eterna inteligência, que não tem nem início nem fim, sabe que ele devia começar ou acabar. Essa inteligência é o teu Verbo, que é o começo porque também nos fala. (AGOSTINHO, 1984, XI, 8.10)

Como o trecho acima indica, se Deus conhece imudavelmente as coisas mudáveis e a sua ordem de sucessão, logo a criação não elimina, mas, ao contrário, fundamenta a motilidade das criaturas.

Tais elementos são aprofundados por Agostinho na sua reflexão sobre o conhecimento divino do que é mudável. Conforme o último excerto revela, o Verbo de Deus não contém, simplesmente, o conhecimento do que está no tempo, mas também da ordem temporal, isto é, do tempo no qual o moto situa-se. Isso implica que, se o tempo é parte do conhecimento divino, ele é uma criatura e, por isso, é um dos seres:

At si cuiusquam volatilis sensus vagatur per imagines retro temporum et te, Deum omnipotentem et omnicreantem et omnitenentem, caeli et terrae artificem, ab opere tanto, 
antequam id faceres, per innumerabilia saecula cessasse miratur, evigilet atque adtendat, quia falsa miratur. Nam unde poterant innumerabilia saecula praeterire, quae ipse non feceras, cum sis omnium saeculorum auctor et conditor? Aut quae tempora fuissent, quae abs te condita non essent? Aut quomodo praeterirent, si numquam fuissent? Cum ergo sis operator omnium temporum, si fuit aliquod tempus, antequam faceres caelum et terram, cur dicitur, quod ab opere cessabas? Id ipsum enim tempus tu feceras, nec praeterire potuerunt tempora, antequam faceres tempora. Si autem ante caelum et terram nullum erat tempus, cur quaeritur, quid tunc faciebas? Non enim erat tunc, ubi non erat tempus.

Se algum espírito leviano, errando entre as imagens vãs do passado, se admirar de que tu, ó Deus, que tudo podes, tudo crias e tudo dominas, autor do céu e da terra, se esse espírito se admirar que tu te tenhas mantido inativo por inúmeros séculos antes de empreenderes a criação, que ele procure despertar e observar que o seu espanto não tem fundamento. De onde poderiam vir e como poderiam transcorrer os inumeráveis séculos, se não os tivesses criado, tu que és o autor e criador de todos os séculos? Que tempo poderia existir, se não fosse estabelecido por ti? E como poderia esse tempo transcorrer, se nunca tivesse existido? Portanto, sendo tu o Criador de todos os tempos - se é que existiu algum tempo antes da criação do céu e da terra - como se pode dizer que cessavas de agir? De fato, foste tu que criaste o próprio tempo, e ele não podia decorrer antes de o criares. (AGOSTINHO, 1984, XI, 13.15) 7

Com base nisso, torna-se claro por que, para o Hiponense, o tempo é a condição do movimento. De fato, se para que haja o movimento, é necessário o conhecimento divino do tempo, e, ao mesmo tempo, se Deus cria no Princípio, isto é, pensando, logo haverá movimento só se

\footnotetext{
${ }^{7}$ No que toca à reflexão agostiniana sobre o tempo e a criação do mundo nos livros XI-XIII das Confessiones, cf.: Boyer (1954, p. 441-448); Meijering (1979), Moreau (1965, p. 276-290); Schulte-Klöcker (2000).
} 
existirá o tempo. Mais precisamente, sendo que o tempo, enquanto ser, corresponde ao instante, isto é, a um átomo temporal que passa do futuro ao passado $^{8}$, pode-se afirmar que, se não houvesse a sucessão discreta dos instantes, não haveria o movimento, o que implicaria a absoluta estaticidade da realidade.

Cabe, contudo, sublinhar que, no que se refere à relação entre tempo e movimento no âmbito da reflexão agostiniana sobre a criação, a análise esboçada não representa a solução unívoca do problema mencionado. No livro XI das Confessiones, torna-se, de fato, evidente uma segunda opção teórica, que corresponde ao reconhecimento do moto como condição do tempo. Mais precisamente, na análise da essência do tempo, o Hiponense afirma:

Quid est ergo tempus? Si nemo ex me quaerat, scio; si quaerenti explicare velim, nescio: fidenter tamen dico scire me, quod, si nihil praeteriret, non esset praeteritum tempus,

\footnotetext{
${ }^{8} \mathrm{Cf}$. "Sendo assim, o tempo presente, o único que pensávamos poder chamar longo, está reduzido apenas ao espaço de um só dia. Mas, se examinarmos atentamente também este dia, chegaremos à conclusão de que nem a duração de um dia é toda ela tempo presente. $\mathrm{O}$ dia e a noite compõem-se de vinte e quatro horas, entre as quais a primeira tem as outras todas como futuras, e a última tem a todas como passadas. E em relação a qualquer hora intermediária, algumas são passadas, outras são futuras. E essa mesma hora é composta de fugitivos instantes: o que se foi é passado, o que ainda resta é futuro. Se pudermos conceber um espaço de tempo que não seja suscetível de ser dividido em minúsculas partes de momentos, só a este podemos chamar tempo presente. Esse, porém, passa tão velozmente do futuro ao passado, que não tem nenhuma duração. Se tivesse alguma duração, dividir-se-ia em passado e futuro. Logo, o tempo presente não tem extensão alguma" (AGOSTINHO, 1984, XI, 15.20). No que concerne às análises agostinianas sobre o estatuto ontológico do instante e a sua função nas reflexões do Hiponense sobre a distentio animi, cf. Quinn (1999, p. 834; p. 835): "The objective character of his solution is corroborated by its agreement with that of Aquinas, here a disciple of Aristotle, dealing with the question, is time dependent on the soul? Time is physically rooted in the ever-flowing now, but, taken in its totality, it is dependent on the soul (in phys. 4.23.5). In apprehending time we mentally retain the prior and posterior factors along with the intervening segments: time as we know it is a psychic time line [...] The measurement of time within the psyche is situated against a backdrop of physical time, for psychic time is unthinkable without its physical counterpart". Para uma crítica do estatuto ontológico do instante enquanto átomo temporal, cf. O’Daly (1988, p. 102).
} 
et si nihil adveniret, non esset futurum tempus, et si nihil esset, non esset praesens tempus. ${ }^{9}$

Por conseguinte, o que é o tempo? Se ninguém me pergunta, eu sei; porém, se quero explicá-lo a quem me pergunta, então não sei. No entanto, posso dizer com segurança que não existiria um tempo passado, se nada passasse; e não existiria um tempo futuro, se nada devesse vir; e não haveria o tempo presente se nada existisse. (AGOSTINHO, 1984, XI, 14.17)

Segundo o trecho acima demonstra, para Agostinho, sem movimento não há tempo, o que coloca em evidência uma oscilação do pensamento agostiniano. De fato, se, à luz da reflexão sobre a criação, o tempo revela-se condição do movimento, por outro lado, com base na análise da essência do tempo, este aparece fundamentado no movimento. Tal ambiguidade, que constitui a primeira das aporias agostinianas em análise, não encontra uma resposta na indicação das diferentes perspectivas teóricas das reflexões de Agostinho. Por certo, apesar das diferenças entre os contextos da análise - o da criação no Verbo e o da relação entre criaturas e movimento -, torna-se evidente que o problema de, se o tempo ou o movimento, é a condição da existência do outro não admite soluções circulares. À luz disso, tratar-se-á, portanto, de analisar se tal problema, assim como o segundo a ser esboçado logo em seguida, representa uma aporia ou se é um exemplo dos limites da compreensão humana da Sagrada Escritura implícitos na ideia agostiniana da relação entre crer e entender. ${ }^{10}$

\section{Matéria e tempo: Confessiones, XII}

A segunda aporia concernente à relação entre tempo e movimento aparece, mais uma vez, na hermenêutica agostiniana do primeiro versículo da Gênese. Nesse caso, para esboçar a natureza do ponto em análise, tratar-se-á de acompanhar as reflexões de Agostinho sobre os

${ }^{9}$ Cf. : Agostinho (1984, XII, 11.14).

${ }^{10}$ Cf.: Agostinho (1984, VI, 5.7-5.8; XII, 14.17-32.43). 
termos céu e terra em Gn. 1,1, para poder, assim, colocar o problema de, se a matéria ou a forma, é a condição do tempo e do movimento.

As reflexões agostinianas sobre tal assunto aparecem ao longo do livro XII das Confessiones. ${ }^{11}$ Nesse contexto teórico, o Hiponense examina, em primeiro lugar, por que, nas páginas do livro da Gênese, há uma dupla menção à criação do céu e da terra. Como afirmar, de fato, que Deus criou, por duas vezes, a mesma coisa? Como pela objeção maniqueísta relativa à ideia da criação, também neste caso a dúvida é a de que a Sagrada Escritura esteja errada e que a dupla menção à criação do céu $(G n .1,1$ e $G n .1,7)$ e da terra $(G n .1,1$ e $G n .1,10)$ seja um erro. Contudo, também neste caso, como já na análise da relação entre criação e movimento, o problema colocado pelas Sagradas Escrituras não enfraquece a fé agostiniana, mas a fortalece. Desse modo, é interessante apontar a estratégia hermenêutica utilizada pelo Hiponense para enfrentar tal dificuldade: se não há erro na autoridade divina e nela aparece uma dupla menção à criação do céu e da terra, isso significa, para Agostinho, que as palavras de Gênese 1,1 referem-se a algo diferente do que indicado por elas, tanto em $G n .1,7$ quanto em $G n .1,10{ }^{12}$

Para determinar o sentido desses termos, Agostinho usa trechos bíblicos mais claros para interpretar os que são mais obscuros. Mais precisamente, no que diz respeito ao termo céu em Gn. 1,1, o Hiponense sugere que ele seja interpretado como uma menção aos anjos, chamados, no Psalmo 113, de céu do céu (AGOSTINHO, 1984, XII, 2.2). Por outro lado, no que concerne à palavra terra, o Hiponense sublinha que, à luz de Gn. 1,2, onde se afirma que As trevas cobriam o abismo, tal termo não indica a terra que vemos, mas algo absolutamente informe, isto é, a matéria:

Et nimirum haec terra erat invisibilis et inconposita et nescio qua profunditas abyssi, super quam non erat lux, quia nulla species erat illi: unde iussisti, ut scriberetur, quod tenebrae erant super abyssum; quid alium quam lucis absentia? [...]

\footnotetext{
${ }^{11}$ No que toca à exegese agostiniana no livro XII das Confessiones, cf.: Bettetini (1995, p. 145-149); Pépin (1987, p. 67-95).

${ }^{12}$ Sobre a hermenêutica da Sagrada Escritura do Hiponense, cf.: Bochet (2004); Ries (1961; p. 231-243; 1963; p. 201-215; 1964, p. 309-329).
} 
Nonne tu, Domine, docuisti me, quod, priusquam istam informem materiam formares atque distingueres, non erat aliquid, non color, non figura, non corpus, non spiritus? Non tamen omnino nihil: erat quaedam informitas sine ulla specie.

Nossa terra era invisível e confusa, um profundo e impenetrável abismo onde não havia luz, pois não tinha forma. Por isso ordenaste que se escrevesse: "As trevas cobriam o abismo". Que significa isso, senão a falta de luz? [...] Não ensinaste, Senhor, a esta alma que te fala, não me ensinaste, Senhor, que antes desta matéria informe receber de ti forma e ordem, nada existia, nem cor, nem figura, nem corpo, nem espírito? Não era, porém, um nada absoluto. Era apenas a massa informe, sem nenhuma aparência exterior. (AGOSTINHO, 1984, XII, 3.3) $)^{13}$

Logo em seguida, Agostinho aprofunda a sua interpretação do primeiro versículo da Gênese. Mais especificamente, o Hiponense coloca em destaque a exigência de esclarecer por que, em $G n$. 1,1, não há indicações concernentes ao momento da criação do céu e da terra. Analisando tal dificuldade, Agostinho afirma, em primeiro lugar, que na Sagrada Escritura não aparece menção ao dia da criação dos anjos e da matéria informe, porque tanto os primeiros quanto a segunda transcendem o tempo (AGOSTINHO, 1984, XII, 9.9). De maneira mais precisa, o Hiponense afirma que os anjos estão fora do tempo, porque contemplam Deus imudavelmente, ao passo que a matéria transcende a temporalidade, porque, enquanto absolutamente informe, não está sujeita ao movimento:

Nimirum enim caelum caeli, quod in principio fecisti, creatura est aliqua intellectualis, quamquam nequaquam tibi, Trinitati, coaeterna, particeps tamen aeternitatis tuae, valde mutabilitatem suam prae dulcedine felicissimae contemplationis tuae cohibet et sine ullo lapsu, ex quo

\footnotetext{
${ }^{13}$ No que concerne à hermenêutica agostiniana do livro XII das Confessiones e, mais precisamente, no que toca à matéria e aos anjos, cf.: Bettetini (1995, p. 139-145); Chaix Ruy (1965, p. 85-88), Pépin (1953, p. 185-274).
} 
facta est, inhaerendo tibi excedit omnem volubilem vicissitudinem temporum. Ista vero informitas, terra invisibilis et inconposita, nec ipsa in diebus numerata est. Ubi enim nulla species, nullus ordo, nec venit quicquam nec praeterit, et ubi hoc non fit, non sunt utique dies nec vicissitudo spatiorum temporalium.

Com efeito, aquele "céu do céu", que fizeste no princípio, é de certa forma uma criatura racional que, embora não coeterna contigo, ó Trinidade, participa todavia da tua eternidade, e, através da suavidade de tua beatífica contemplação, reduz fortemente a sua própria mobilidade. Desde que foi criada, permanece sempre unida a ti, sem movimento nenhum, e se sobrepõe às vicissitudes passageiras do tempo. Quanto a essa amorfia que é "a terra invisível" e informe, não foi contada entre os dias. De fato, onde não existe forma nem ordem, nada vem e nada passa; e onde tal não se dá, não existem certamente nem dias nem sucessão de espaços de tempo. (AGOSTINHO, 1984, XII, 9.9) ${ }^{14}$

Como o trecho acima sugere, a matéria, sendo absolutamente informe, não pode mudar e, por isso, está fora do tempo. Nesse sentido, torna-se evidente que, para que haja tanto o movimento quanto o tempo, é necessário que a forma forje a matéria, assim como acontece na criação divina do mundo:

de qua terra invisibili et inconposita, de qua informitate, de quo paene nihilo faceres haec omnia, quibus iste mutabilis mundus constat et non constat, in quo ipsa mutabilitas apparet, in qua sentiri et dinumerari possunt tempora, quia rerum mutationibus fiunt tempora, dum variantur et vertuntur species, quarum materies praedicta est terra invisibilis.

Desta terra invisível e sem ordem, dessa informidade, deste quase nada, fizeste tudo aquilo de que é formado e não formado este mundo mutável, no qual se manifesta esta

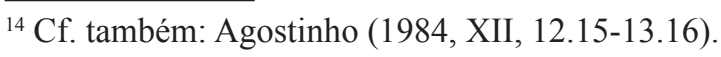


mobilidade, pela qual se pode sentir e medir o tempo. De fato, este tempo é feito da mudança das coisas, da variação e da sucessão das formas, cuja matéria é a terra invisível, da qual falamos anteriormente. (AGOSTINHO, 1984, XII, 8.8)

Como as palavras de Agostinho indicam, o tempo começa a partir do movimento, e este, por sua vez, pressupõe a presença e o agir da forma. À luz disso, é evidente por que a menção dos dias da criação refere-se só ao que foi feito a partir da matéria informe. De fato, se o tempo requer o movimento, e o movimento requer a forma, haverá dias só se houver forma:

Tu enim, Domine, fecisti mundum de materia informi, quam fecisti de nulla re paene nullam rem, unde faceres magna, quae miramur filii hominum. Valde enim mirabile hoc caelum corporeum, quod firmamentum inter aquam et aquam secundo die post conditionem lucis dixisti: fiat, et sic est factum. Quod firmamentum vocasti caelum, sed caelum terrae huius et maris, quae fecisti tertio die dando speciem visibilem informi materiae, quam fecisti ante omem diem.

De fato, Senhor, "tu criaste o universo de uma matéria informe". Tiraste do nada um quase nada, para dele fazer as coisas grandes, que nós, filhos dos homens, admiramos. É realmente maravilhoso este céu corpóreo, este firmamento que separa umas águas das outras, que criaste no segundo dia depois da criação da luz, quando disseste: "Faça-se: e assim se fez". Chamaste céu a esse firmamento, mas o céu desta terra e deste mar é que fizeste no terceiro dia, dando forma visível à matéria informe que tinhas criado antes do início dos dias. (AGOSTINHO, 1984, XII, 8.8)

Com base nisso, pode-se afirmar que, para Agostinho, a forma é condição do movimento e do tempo, o que parece indicar a sua primazia sobre a matéria na fundamentação do moto e do tempo:

Ecce nescio quid informe in istis mutationibus rerum extremarum atque infimarum, et quis dicet mihi, nisi quisquis per inania cordis sui cum suis phantasmatis vagatur 
e volvitur, quis nisi talis dicet mihi, quod deminuta atque consumpta omni specie, si sola remaneat informitas, per quam de specie in speciem res mutabatur et vertebatur, possit exhibere vices temporum? Omnino enim non potest, quia sine varietate motionum non sunt tempora: et nulla varietas, ubi nulla species.

Com efeito, vejo um não sei que de informe nas mudanças das últimas e ínfimas criaturas. E quem, senão aqueles que se revolvem no seu interior em companhia das próprias fantasias, quem poderá dizer-me que essa informidade poderia mostrar em si a vicissitude dos tempos? Não, tal hipótese é impossível, pois não há tempo sem variedade de movimentos, e não há variedade alguma onde não há forma. (AGOSTINHO, 1984, XII, 11.14)

Cabe, contudo, apontar que, também neste caso, a reflexão esboçada não constitui a única solução da dificuldade em análise. Com efeito, as reflexões do livro XII das Confessiones colocam em evidência a possibilidade de uma segunda opção teórica, que coincide com a ideia de que a matéria informe seria a condição do movimento e do tempo. Mais precisamente, no âmbito da reflexão sobre os movimentos de formação e corrupção, o Hiponense afirma que tais motos somente podem se realizar caso exista algo informe, isto é, a matéria:

et intendi in ipsa corpora eorumque mutabilitatem altius inspexi, qua desinut esse quod fuerant et incipiunt esse quod non erant, eundemque transitum de forma in formam per informe quiddam fieri suspicatus sum, non per omnino nihil.

Fixei a atenção nos próprios corpos, analisando mais profundamente sua mutabilidade, pela qual cessam de ser aquilo que eram e começam a ser o que não eram. Suspeitei que essa transição de uma forma para outra se fazia por meio de algum ser informe, e não pelo nada absoluto. (AGOSTINHO, 1984, XII, 6.6) 
Como tal trecho mostra, para que haja tanto a formatio quanto a corruptio precisa-se de algo que, apesar da informidade, possa receber ${ }^{15}$ ou perder forma, isto é, a matéria, que se revela, assim, em si mesma, a origem atempora $1^{16}$ do moto e do tempo:

Mutabilitas enim rerum mutabilium ipsa capax est formarum omnium, in quas mutantur res mutabiles. Et haec quid est? Numquid animus? Numquid corpus? Numquid species animi vel corporis? Si dici posset «nihil aliquid» et «est non est», hoc eam dicerem; et tamen iam utcumque erat, ut species caperet istas visibiles et conpositas.

A própria mutabilidade das coisas é capaz de tomar todas as formas em que se transfiguram as coisas mutáveis. E essa mutabilidade, que é? Um espírito? Um corpo? Ou talvez uma espécie de espírito ou de corpo? Se fosse possível dizer "um certo nada que é e não é", eu o diria. No entanto, de uma certa maneira já existia, para poder assumir tais aspectos visíveis e complexos. (AGOSTINHO, 1984, XII, 6.6)

Tais reflexões colocam em evidência, mais uma vez, uma oscilação no pensamento do Hiponense. De fato, se na análise da atemporalidade da matéria apareceu claramente que a forma é a condição

\footnotetext{
${ }^{15} \mathrm{Cf}$. "Mas chamo eu hýle certa matéria absolutamente informe e sem qualidade alguma a partir da qual se formam todas as qualidades que percebemos pelos nossos sentidos, como o sustentaram os antigos filósofos. Por isso a madeira do bosque se denomina em grego ṽ $\eta_{n}[h y ́ l e \bar{e}$, porque é matéria apta para que a trabalhem - não, pois, para que ela produza por si mesma alguma coisa, mas para que dela seja feito algo. Não se deve dizer, portanto, que seja má esta hýlē que de modo algum pode ser percebida pelos sentidos, e que apenas se pode conceber como privação absoluta de toda e qualquer espécie. Tem, pois, em si essa matéria capacidade para receber determinadas formas, porque, se não fosse capaz de receber a forma que lhe imprime o artífice, por certo não se chamaria matéria" (AGOSTINHO, 2006, 18). Cabe sublinhar que, assim como as mesmas palavras de Agostinho sugerem, a capacidade de receber forma da matéria não é, simplesmente, a condição da existência do movimento e do tempo, mas é, também, a condição da bondade da hyle. De feito, se todas as criaturas são boas porque têm modus, species e ordo, logo a matéria, que é absolutamente privada deles, só poderá ser boa pela sua capacidade de recebê-los.

${ }^{16}$ Agostinho (1984, XII, 29.40).
} 
do movimento e do tempo, nas reflexões sobre formatio e corruptio, foi a matéria a revelar-se fundamento do tempo e do movimento. Assim como pela primeira aporia, o problema mencionado não encontra uma solução na indicação das diferentes perspectivas da análise agostiniana. Por certo, apesar dos âmbitos teóricos serem distintos, é evidente que também o problema de, se a forma ou a matéria, é condição da existência do tempo e do movimento não admite soluções circulares. Portanto, tratar-se-á agora de analisar se as duas questões aqui esboçadas são autênticas aporias ou se elas exprimem o limite da compreensão humana das Sagradas Escrituras. ${ }^{17}$

\section{Ratio e fides: Confessiones, VI}

Para entender a reflexão agostiniana sobre a natureza e as possibilidades da compreensão humana da autoridade divina, e poder, assim, esclarecer o sentido das aporias encontradas ao longo da análise agostiniana de $G n$. 1,1, é necessário esboçar a relação entre ratio e fides assim como aparece no livro VI das Confessiones. Nesse contexto teórico, Agostinho, que não é mais maniqueísta mas que ainda não é católico, à luz dos sermões de Ambrosio, pergunta-se se é possível acreditar nas Sagradas Escrituras e fundamentar nelas a busca filosófica. No exame desse assunto, Agostinho considera, em primeiro lugar, se é possível acreditar em algo, para logo depois analisar se é possível dar assentimento aos conteúdos das Sagradas Escrituras. O Hiponense reconhece assim, in primis, que na nossa experiência cotidiana nós acreditamos firmamente em coisas que não são certas, como, por exemplo, a identidade dos nossos pais ou os contos dos amigos, e acrescenta que uma completa suspensão do assentimento significaria desistir de qualquer ação:

Deinde paulatim tu, Domine, manu mitissima et misericordissima pertractans et conponens cor meum, consideranti, quam innumerabilia crederem, quae non viderem neque cum gererentur adfuissem, sicut tam multa in historia gentium, tam multa de locis atque urbibus, quae non

${ }^{17}$ Agostinho (1984, VI, 5.7-5.8; XII, 14.17-32.43). 
videram, tam multa amicis, tam multa medicis, tam multa hominibus aliis atque aliis, quae nisi crederentur, omnino in hac vita nihil ageremus, postremo quam inconcusse fixum fide retinerem, de quibus parentibus ortus essem, quod scire non possem, nisi audiendo credidissem.

E enquanto tua mão suave e misericordiosa plasmava e formava pouco a pouco o meu coração, eu refletia na infinidade de fatos em que acreditava, sem tê-los visto ou deles ter sido testemunha. Assim, os muitos episódios da história da humanidade, a existência de lugares e cidades nunca visitados, conhecimentos recebidos de amigos, de médicos e de tantos outros em que temos de acreditar, sob pena de nada podermos realizar na vida. Enfim, como estava absolutamente seguro da identidade de meus pais, o que não poderia saber sem acreditar no que ouvia (AGOSTINHO, 1984, VI, 5.7).

Em seguida, Agostinho aprofunda tais reflexões e pergunta-se se é possível acreditar na Sagrada Escritura, apesar do seu conteúdo não ser evidente. Analisando tal dificuldade, o Hiponense afirma que se há um grande número de povos que acreditam nas Sagradas Escrituras é porque Deus quer que o homem O busque por meio delas:

Ideoque cum essemus infirmi ad inveniendam liquida ratione veritatem et ob hoc nobis opus esset auctoritate sanctarum Litterarum, iam credere coeperam nullo modo te fuisse tributurum tam excellentem illi scripturae per omnes iam terras auctoritatem, nisi et per ipsam tibi credi et per ipsam te quaeri voluisses.

Portanto, sendo os homens incapazes de encontrar a verdade mediante a razão pura, e tendo necessidade do apoio da Sagrada Escritura, eu já principiava a crer que não concederias tanta autoridade por toda a terra a estes Livros Sagrados se não tivesses querido que se acreditasse em ti e se buscasse a ti através deles (AGOSTINHO, 1984, VI, 5.8). 
Como o trecho acima indica, para alcançar a Verdade, precisa-se da fé na Sagrada Escritura, o que é expresso por Agostinho na fórmula credo ut intelligam, intelligo ut credam. Nessa perspectiva, torna-se evidente que se a busca da Verdade se fundamenta na autoridade divina, então a filosofia coincide com a hermenêutica da Sagrada Escritura. Cabe, contudo, sublinhar que o Hiponense afirma que a nossa compreensão da autoridade divina não é completa, mas parcial. Tal afirmação sugere que na interpretação dos Livros Sagrados apareçam dificuldades não perfeitamente esclarecíveis, como, por exemplo, a da relação de anterioridade da matéria informe à matéria formada na criação. Na análise desse ponto, o Hiponense esboça, em primeiro lugar, quais seriam as possíveis formas de antecedência, para depois indicar qual seria a que é própria da matéria informe. Apesar de distinguir entre quatro formas de anterioridade - por eternidade, tempo, valor e origem -, Agostinho reconhece que a da matéria informe à matéria formada não corresponde a nenhuma delas, mas que tal anterioridade é uma antecedência nem puramente temporal nem puramente por origem:

Hoc exemplo qui potest intellegat materiam rerum primo factam et appellatam caelum et terram, quia inde facta sunt caelum et terra, nec tempore primo factam, quia formae rerum exserunt tempora, illa autem erat informis iamque in temporibus simul animadvertitur, nec tamen de illa narrari aliquid potest, nisi velut tempore prior sit, cum pendatur extremior, quia profecto meliora sunt formata quam informia, et praecedatur aeternitate creatoris, ut esset de nihilo, unde aliquid fieret.

Com esse exemplo [scil. o do canto e do som], podemos compreender como a matéria do universo foi feita antes, e foi chamada céu e terra, porque dela foram feitos o céu e a terra. Não foi criada primeiro em sentido cronológico, porque o tempo é expresso pelas formas das coisas, e essa matéria era informe enquanto agora é perceptível juntamente com o tempo. Todavia, nada se pode expor acerca dessa matéria, a não ser atribuir-lhe certa prioridade cronológica, se bem que seja considerada o menor de todos os seres, pois 
a matéria dotada de forma tem mais valor que a informe. E esta matéria informe foi precedida pela eternidade do Criador, que a fez para que as coisas fossem extraídas do nada (AGOSTINHO, 1984, XII, 29.40). ${ }^{18}$

Conforme fica evidente, nesta solução agostiniana, afirma-se da anterioridade da matéria só o que pode ser dito e conhecido, o que sugere que tanto dela quanto das Sagradas Escrituras podemos ter somente uma compreensão parcial e incompleta.

À luz disso, cabe agora esclarecer se os problemas encontrados nas reflexões agostinianas dos livros XI e XII das Confessiones são expressão dos limites da nossa compreensão das Sagradas Escrituras ou se eles são aporias. Nesse sentido, é importante lembrar que o Hiponense reconhece que a compreensão humana da autoridade divina é parcial, mas não admite que essa compreensão possa ser contraditória. Assim, se tanto a primeira quanto a segunda questão implicam contradições, isso significa que as duas não representam os limites do conhecimento humano

${ }^{18}$ Sobre o problema da natureza da anterioridade da matéria informe à matéria formada, cf. Bettetini (1995, p. 147-148): "Se io fossi Mosè: l'idea non dispiace ad Agostino, che dopo aver formulato la dichiarazione di disponibilità delle righe precedenti, ritorna su questa possibilità. Se io avessi dovuto spiegare la creazione dell'universo, e in particolare il problema della materia informe, come mi sarei espresso? E il capitolo 40 è un esperimento in questa direzione, una lunga metafora in cui ancora una volta il mondo è paragonato a un canto. Seguiamola passo passo: riprendendo il tema della materia informe che viene successivamente formata, Agostino chiarisce in che senso si debbano intendere i «prima» e i «poi»: 'per l'eternità, ad esempio, Dio precede ogni cosa; per il tempo, il fiore precede il frutto; per il valore il frutto precede il fiore; per l'origine il suono precede il canto'. La prima e l'ultima priorità sono 'difficilissime' da capire: come comprendere che possa esistere un suono privo di forma in qualche modo precedente il canto, che non è altro che un suono provvisto di forma? E così, come comprendere che sia esistita una materia informe precedente la materia formata? Si tratta di una 'precedenza di origine', né temporale né di valore, poiché il suono riceve forma per essere canto e non viceversa. E prosegue Agostino: 'da questo esempio comprenda chi può come la materia dell'universo fu creata prima, e chiamata cielo e terra, perché ne furono tratti il cielo e la terra'. Di essa non si può predicare nulla (nec tamen de illa narrari aliquid potest), se non attribuirle una certa priorità nel tempo, sebbene la si debba considerare l'infimo degli esseri, poiché priva di forma, e preceduta nell'eternità dal Creatore". No que concerne ao problema em análise, cf. também: Chaix Ruy (1965, p. 86). 
da autoridade divina, mas oscilações do pensamento agostiniano. Isso sugere, portanto, que as relações entre tempo e movimento esboçadas pelo Hiponense nos livros XI e XII das Confessiones constituem questões sem solução, o que indica, assim, que elas são autênticas aporias da filosofia de Agostinho.

\section{Referências}

AGOSTINHO. Confissões. Tradução de M. L. Jardim Amarante. São Paulo: Paulus, 1984.

AGOSTINHO. A natureza do bem. Tradução de C.A. Nougué. RJ: Sétimo Selo, 2006.

BETTETINI, M. Pensare il nulla, dire la materia: libertà ed ermeneutica nel libro XII delle Confessioni. In: ALICI, L.; PICCOLOMINI, R.; PIERETTI, A. (Org.). Il mistero del male e la libertà possibile: linee di antropologia agostiniana. Roma: IPA, 1995. p. 139-149.

BOCHET, I. Le Firmament de l'Écriture. Paris: Études Augustiniennes, 2004.

BOYER, C. Éternité e création dans les derniers livres des Confessions. Giornale di Metafisica, Genova, v. 9, p. 441-448, 1954.

CALLAHAN, J. F. Four Views of Time in Ancient Philosophy. CambridgeMassachusetts: Harvard University Press, 1948.

CATAPANO, G. (Org.). Sant'Agostino. Il Tempo. Roma: Città Nuova Editrice, 2007.

CHAIX RUY, J. La création du monde d'après Augustin. Revue des Études Augustiniennes, Paris, v. 11, p. 85-88, 1965.

DECRET, F. Introduzione Generale. In: Sant'Agostino. Polemica con $i$ Manichei. Roma: Città Nuova Editrice, 1997. p. VII-CXV.

DI SILVA, M. F. Il concetto agostiniano di futuro: Confessiones, XI. Kriterion, Belo Horizonte, v. 56, p. 129-148, 2015.

D’ONOFRIO, G. Il pensiero «convertito»: il giovane Agostino. Archivio di Filosofia, Roma, v. 59, p. 323-337, 1991. 
MEIJERING, E. P. Augustin über Schöpfung, Ewigkeit und Zeit. Das elfte Buch der Bekenntnisse. Leiden: Brill, 1979.

MOREAU, J. Le temps et la création selon Saint Augustin. Giornale di Metafisica, Genova, v. 20, p. 276-290, 1965.

O’DALY, G. La filosofia della mente in Agostino. Palermo: Augustinus, 1988.

PÉPIN, J. Recherches sur le sens et les origens de l'expression caelum caeli dans le livre XII des Confessions de Saint Augustin. Archivum latinitatis Medii Aevi, Paris-Leiden-Genève, p. 185-274, 1953.

PÉPIN, J. Le livre XII des Confessions, ou éxègese et confession. In: SOLIGNAC, A. et al. Le Confessioni di Agostino d'Ippona. Libri X-XIII. Palermo: Edizioni Augustinus, 1987, p. 67-95.

QUINN, J. M. TIME. In: FITZGERALD, A.; CAVADINI, J. (Org.). Augustine through the ages: An Encyclopedia. MI: Wm. B. Eerdmans Publications, 1999. p. 832-838.

REY PUENTE, F.; BARACAT J. J. (Org.). Tratados sobre o tempo. Aristóteles, Plotino, Agostinho. Belo Horizonte: Editora UFMG, 2014.

RIES, J. La Bible chez S. Augustin e chez les manichées. Revue des Études Augustiniennes, Paris, v. 7, p. 231-243, 1961; v. 9, p. 201-215, 1963; v. 10, p. 309-329, 1964.

RIES, J. Saint Augustin et le Manichéisme à la lumiére du livre III des Confessions. In RIES, J. et al. Le Confessioni di Agostino d'Ippona. Libri III- $V$. Palermo: Edizioni Augustinus, 1984. p. 7-26.

SCHULTE-KLÖCKER, U. Das Verhältnis von Ewigkeit und Zeit als Widerspiegelung der Beziehung zwischen Schöpfer und Schöpfung. Eine textbegleitende Interpretation der Bücher XI-XIII der «Confessiones» des Augustinus. Bonn: Borengässer, 2000.

Recebido em 30 de julho de 2017. Aprovado em 12 de outubro de 2017. 